\title{
The ischemic preconditioning and postconditioning effect on the intestinal mucosa of rats undergoing mesenteric ischemia/reperfusion procedure ${ }^{1}$
}

\author{
Efeito do pré e pós-condicionamento isquêmico sobre a mucosa intestinal de ratos \\ submetidos ao processo de isquemia e reperfusão mesentérica
}

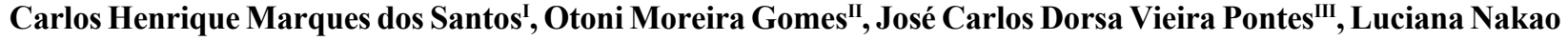 \\ Odashiro Miiji ${ }^{\mathrm{IV}}$, Marco Aurélio Feltrin Bispov

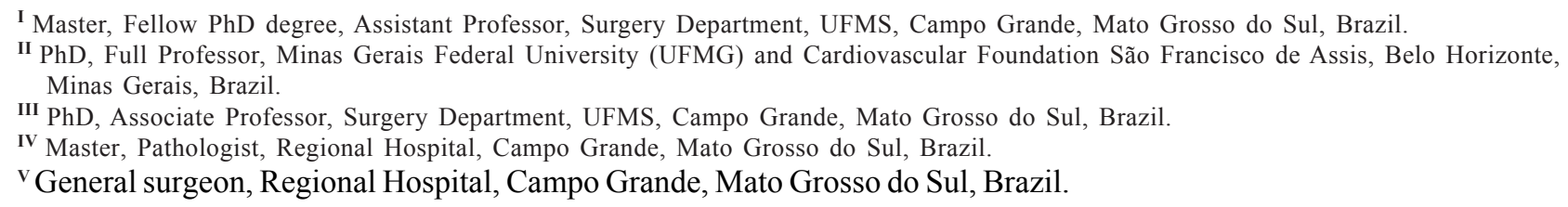

\begin{abstract}
Purpose: To evaluate the effect of the ischemic preconditioning and the ischemic postconditioning over the tissue injury in the intestinal mucosa of rats undergoing the procedure of mesenteric ischemia and reperfusion. Methods: Thirty Wistar rats were studied, divided in three groups: group A, undergoing mesenteric ischemia (30 minutes) and reperfusion (60 minutes); group B, mesenteric ischemia and reperfusion preceded by ischemic preconditioning; group C, mesenteric ischemia and reperfusion and, before the beginning of reperfusion, the ischemic postconditioning was performed. At the end, a segment of the small intestine was dissected for histological analysis. The results were evaluated using the CHIU et al. ${ }^{6}$ classification followed by the statistic treatment. Results: The mean values of the tissue injury levels were: group A, 3.5; group B, 1.2; and group C, 1. The difference between the result of group A with the results of groups B and C was considered statistically significant $(\mathrm{p}<0,05)$. Conclusion: The ischemic preconditioning and postconditioning are able to minimize the tissue injury in the intestines of rats that underwent the procedure of mesenteric ischemia and reperfusion. Key words: Ischemia. Reperfusion. Ischemic Preconditioning. Rats.
\end{abstract}

\section{RESUMO}

Objetivo: Avaliar o efeito do pré e pós-condicionamento isquêmico sobre a lesão tecidual na mucosa intestinal de ratos submetidos ao processo de isquemia e reperfusão mesentérica. Métodos: Foram estudados 30 ratos Wistar, distribuídos em três grupos: grupo A, em que se realizou isquemia (30 minutos) e reperfusão (60 minutos) mesentérica; grupo B, isquemia e reperfusão mesentérica precedidos pelo pré-condicionamento isquêmico; grupo $C$, isquemia e reperfusão mesentérica e, precedendo o início da reperfusão, foi realizado o pós-condicionamento isquêmico. Ao final, ressecou-se um segmento do intestino delgado para análise histológica. Avaliaram-se os resultados pela classificação de CHIU e col. ${ }^{6}$ e procedeu-se o tratamento estatístico. Resultados: As médias dos graus de lesão tecidual foram: grupo A, 3,5; grupo B, 1,2; grupo C, 1. A diferença entre o resultado do grupo A com os resultados dos grupos B e C foi considerada estatisticamente significativa $(\mathrm{p}<0,05)$. Conclusão: $O$ pré e pós-condicionamento isquêmico foram capazes de minimizar a lesão tecidual na mucosa intestinal de ratos submetidos ao processo de isquemia e reperfusão mesentérica.

Descritores: Isquemia. Reperfusão. Precondicionamento Isquêmico. Ratos.

1. Research performed at Laboratory of Research, Mato Grosso do Sul Federal University (UFMS), Campo Grande, Mato Grosso do Sul, Brazil. 


\section{Introduction}

In 1986 two studies brought a great advance for the treatment of ischemia and reperfusion. The first was the Parks and Granger's study ${ }^{1}$, showing that reperfusion is more damaging than ischemia alone, something that was still unknown, causing a great change in the current concepts and generating various studies that elucidated the physiopathology of ischemia and reperfusion. The second study of great importance was the one of Murry et $\mathrm{al}^{2}$ who brought the concept of ischemic preconditioning (IPr) as a way to minimize the injuries of ischemia and reperfusion. These authors described the beneficial effect of short periods of coronary occlusion followed by short periods of reperfusion, before the ischemic phase is initiated, noticing a reduction of ischemic myocardial injury in dogs.

However, there are cases in which ischemia is identified when the injuries have already occurred, having no chance to use the preconditioning.

In 2003, Zhao et al. ${ }^{3}$ presented the concept of ischemic postconditioning (IPo), which consists of one or more short cycles of reperfusion followed by one or more short cycles of ischemia, immediately after an ischemic phase and before the permanent reperfusion occurs. These authors showed that the IPr was as efficient as the IPo in preventing reperfusion injuries.

This study led to others that have similarly showed the capacity of the IPo in preventing ischemic and reperfusion injuries as much as the $\mathrm{IPr}^{4}$.

If the efficiency of IPo is confirmed in human beings, this may be a great advance in the treatment of ischemia and reperfusion, once it is very common to make the diagnosis of the injuries of this procedure when ischemia has already occurred and, therefore, there is no possibility of using the IPr. In experimental models, there is evidence of a probable protective effect of IPo on the intestinal mucosa of rats that underwent mesenteric ischemia and reperfusion ${ }^{5}$.

Consequently, regarding the current evidences of the use of IPo to minimize the tissue injuries caused by the ischemia/reperfusion procedure, it is of vital importance, and it is the aim of this study, to comparatively evaluate the capacity of IPr and IPo to minimize intestinal tissue injury in the procedure of mesenteric ischemia and reperfusion.

\section{Methods}

This study received the previous approval of the Ethics Committee Mato Grosso do Sul. Federal University. Thirty Wistar male adult rats (Rattus norvegicus albinus, Rodentia, Mammalia) were studied, with weight ranging from 270 to 350 grams, average of 305 grams, from the laboratory of Mato Grosso do Sul.Federal University.

The animals were distributed into the following groups (Figure 1):

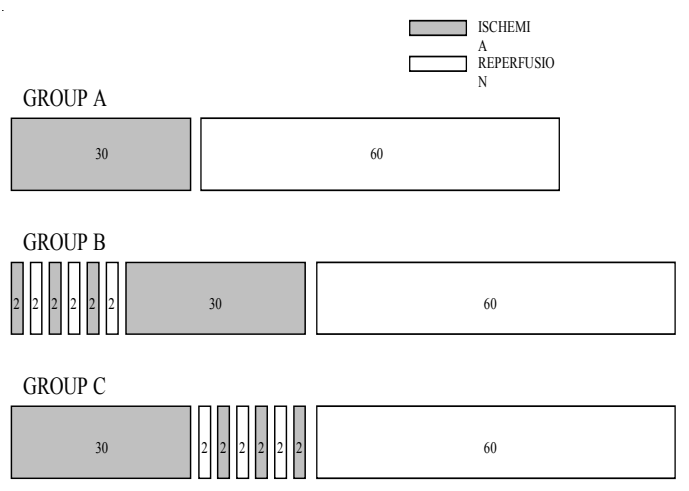

FIGURE 1 - Ischemia and reperfusion periods schematic demonstration in the groups $\mathrm{A}, \mathrm{B}$ and $\mathrm{C}$ (the numbers correspond to time in minutes)

- Group A - Ischemia and Reperfusion: ten rats underwent intestinal ischemia for 30 minutes through occlusion of the mesenteric artery with a vascular clamp, followed by a 60 -minute reperfusion.

- Group B - Ischemic preconditioning: ten rats underwent a 30-minute ischemia through the occlusion of the mesenteric artery with a vascular clamp and 60 minutes of reperfusion. The ischemic phase was preceded by three cycles of ischemia ( 2 minutes each) alternated with three cycles of reperfusion ( 2 minutes each).

- Group C - Ischemic postconditioning: ten rats underwent ischemic procedure for 30 minutes through the occlusion of the mesenteric artery with a vascular clamp and reperfusion for 60 minutes. Between ischemia and reperfusion, three cycles of reperfusion (2 minutes each) alternated with three cycles of ischemia ( 2 minutes each) were performed.

The animals were weighed using an electronic scale and anesthetized with an intraperitonial administration of 2:1 Chloridrate of Cetamine, $50 \mathrm{mg} / \mathrm{ml}$, and Chloridrate of Xilazin, $20 \mathrm{mg} / \mathrm{ml}$, respectively, in a dose of $(0.1 \mathrm{ml} / 100 \mathrm{~g})$.

The rats underwent a 4-centimeter medium-lengthwise laparotomy, exposure of the small intestine, identification and dissection of the mesenteric artery.

In group $\mathrm{A}$, the mesenteric artery was occluded with a vascular clamp for thirty minutes (ischemic cycle). After the artery was clamped, the small intestine was repositioned inside the abdominal cavity and the surgical wound was closed with 4-0 monofiber nylon stitches. After the ischemic cycle, the abdominal cavity was reopened through removal of the stitches and the vascular clamp was taken, starting the reperfusion cycle, lasting 60 minutes. In the three groups, as the reperfusion cycle started, the abdomen was again closed with continuous 4-0 monofiber nylon stitches (mononylon ${ }^{\circledR}$ ) until the end of the experiment.

In group $\mathrm{B}$, before the ischemic cycle (30 minutes), the ischemic preconditioning was performed through three cycles of ischemia, lasting two minutes each (occlusion of the mesenteric artery with a vascular clamp), alternated with three cycles of reperfusion, also lasting two minutes each 
(removal of the vascular clamp from the mesenteric artery). After the ischemic cycle, reperfusion was performed for 60 minutes.

In group $\mathrm{C}$ the ischemic (30 minutes) and reperfusion (60 minutes) cycles were performed. Preceding the reperfusion cycle, the ischemic postconditioning was performed through three cycles of reperfusion (removal of the vascular clamp from the mesenteric artery) lasting two minutes each, alternated with three cycles of ischemia (occlusion of the mesenteric artery with a vascular clamp), also lasting two minutes each.

After the reperfusion cycle was completed in the three groups, the abdominal cavity was again opened through the removal of the stitches and a one-centimeter segment of the ileum was dissected, five centimeters proximal to the ileocaecal junction, which was opened in its antimesenteric border, washed with a saline solution and put in a formaldeid solution at $10 \%$ for further histological analysis. anesthesia.

The animals were euthanized under deep

After being in a formaldeid solution at $10 \%$, the dissected intestinal segments were histologically analyzed and the slides were stained with hematoxilin-eosin, and analyzed by the pathologist with an optic microscope, without him knowing which group each rat belonged to, and they were classified according to the tissue injury level in accordance to Chiu et al. ${ }^{6}$ :

- Level 0: mucosa without changes.

- Level 1: well-constituted villosities, no cellular lysis or inflammatory process, although there is formation of Grunhagen's sub-epithelial space.
- Level 2: presence of cellular lysis, formation of Grunhagen's sub-epithelial space and increased spacing among the villosities.

- Level 3: destruction of the free villosities section, presence of dilated capillaries and inflamed cells.

- Level 4: structural destruction of the villosities, only traces of some villosities, formed by inflamed cells and necrotic material, with hemorrhage and basal glandular ulceration.

- Level 5: destruction of all the mucosa, no glandular structure can be seen, only the amorphous material laying on the sub-mucosa tissue.

The results received statistical treatment, using the Kruskal-Wallis non-parameter test, with a significance level of $\mathrm{p}<0,05$. The program Bioestat 2.0 was used.

\section{Results}

After the histological analysis of the level of the intestinal mucosa injury according to Chiu and col. ${ }^{6}$, the following results were found: (Table 1 and Figure 2):

In group A the mean value of the tissue injury level was 3.5. Half the animals in this group had level 3 injuries and the other half had level 4 injuries.

In group B the mean value of the tissue injury level was 1.2. In this group, three animals did not have injuries (level 0), four had level 1 injuries, one had level 2 injuries and two had level 3 injuries.

In group $\mathrm{C}$ the mean value of the tissue injury level was 1 . Three animals did not have injuries (level 0 ), five had level 1 injuries, one had level 2 injuries and one had level 3 injuries.

TABLE 1 - Results of the histological analysis of the level of the intestinal mucosa injury in groups A, B and C according to CHIU and col. ${ }^{6}$

\begin{tabular}{l|ccc}
\hline \multirow{2}{*}{ RATS } & \multicolumn{3}{c}{ LEVELSOFMUCOSALINJURY } \\
\cline { 2 - 4 } & GROUP A & GROUP C & GROUP B \\
\hline \multirow{2}{*}{1} & 3 & 0 & 0 \\
2 & 3 & 1 & 1 \\
3 & 3 & 1 & 3 \\
4 & 3 & 2 & 1 \\
5 & 4 & 3 & 2 \\
6 & 4 & 3 & 1 \\
7 & 4 & 0 & 0 \\
8 & 4 & 0 & 0 \\
9 & 4 & 1 & 1 \\
10 & 3 & $\mathbf{1 , 2}$ & 1 \\
\hline \multirow{2}{*}{ MEANVALUE } & $\mathbf{3 , 5}$ & & $\mathbf{1 , 0}$ \\
\hline
\end{tabular}




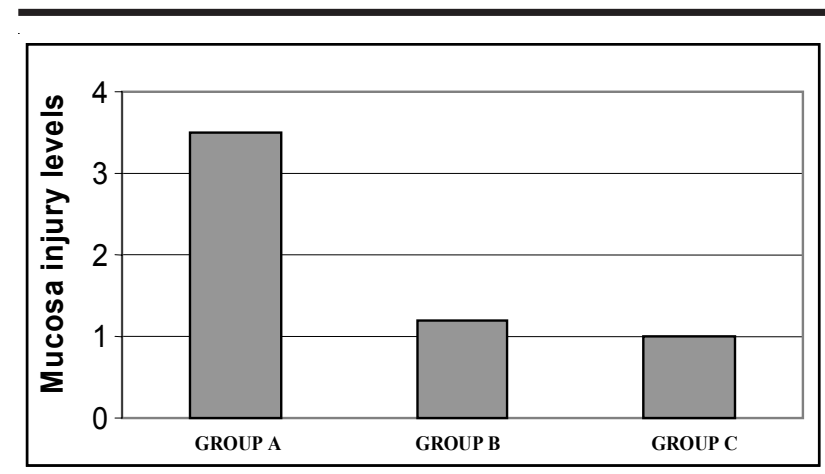

FIGURE 2 - Histological analysis comparative graph of intestinal mucosal injury of rats of the groups $\mathrm{A}, \mathrm{B}$ and $\mathrm{C}$ according to $\mathrm{CHIU}$ and col. ${ }^{6}$

The results of the histological analysis can be observed in the Figures 3 to 7.

Using the Kruskal-Wallis non-parameter test, we observed that groups B and C are similar from the statistical point of view $(p=0.7507)$, yet there is a statistically significant difference between them and group A (between A and B $\mathrm{p}=0.0004$ and between $\mathrm{A}$ and $\mathrm{C} \mathrm{p}=0.0002$ ).

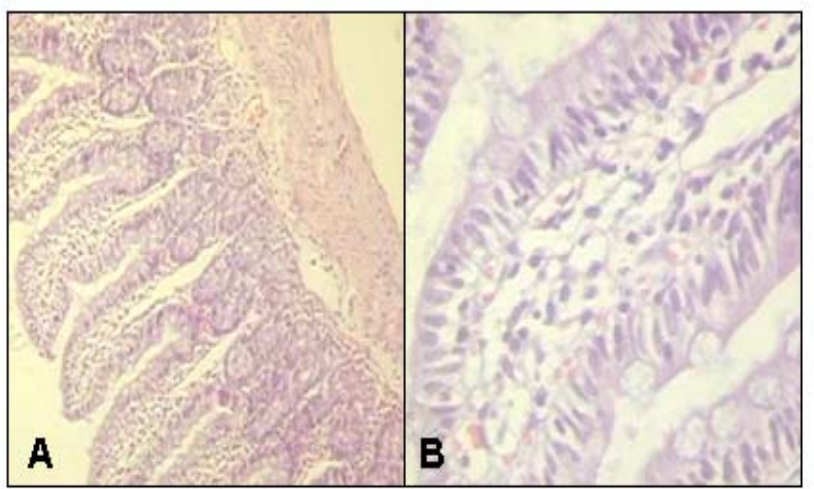

FIGURE 3 - Microphotograph of level 0 of Chiu's Score $^{6}$ of intestinal mucosa (HE, A x100, B x400)

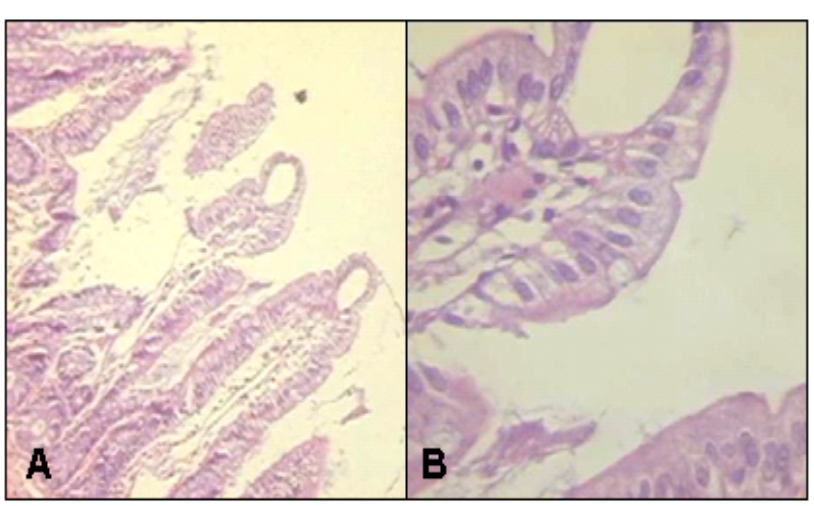

FIGURE 4 - Microphotograph of level 1 of Chiu's Score' of intestinal mucosa (HE, A x100, B x400)

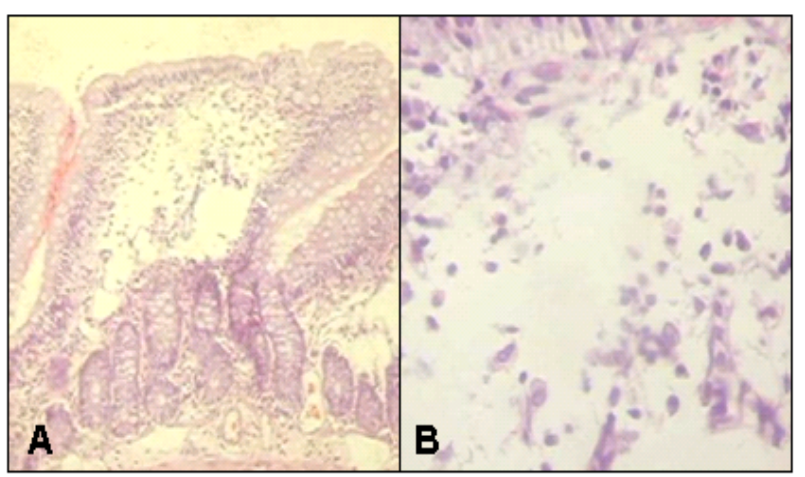

FIGURE 5 - Microphotograph of level 2 of Chiu's Score' of intestinal mucosa (HE, A x100, B x400)

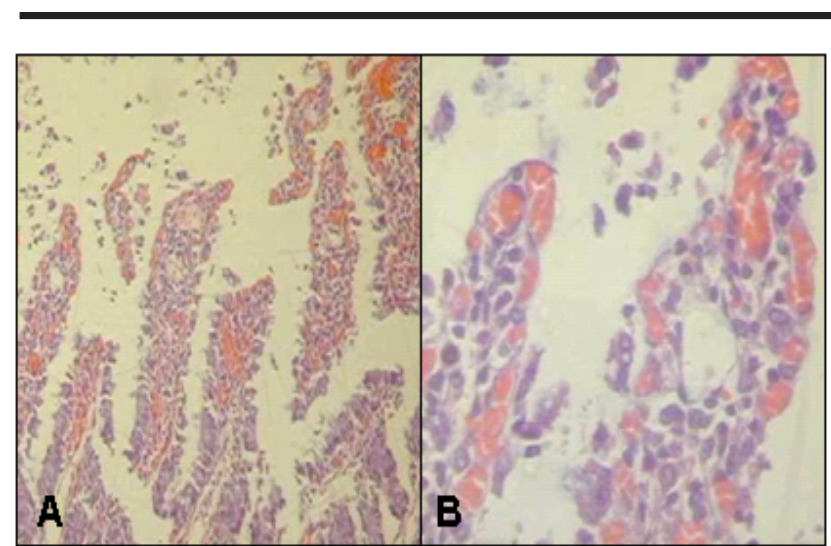

FIGURE 6 - Microphotograph of level 3 of Chiu's Score' of intestinal mucosa (HE, A x100, B x400)

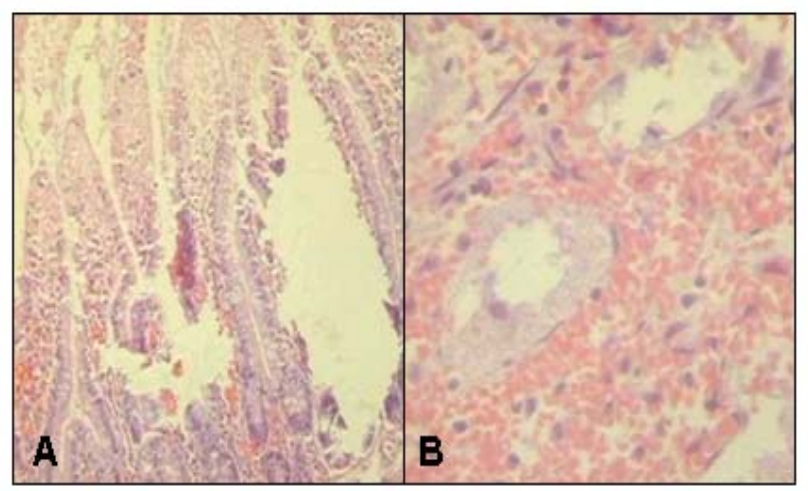

FIGURE 7 - Microphotograph of level 4 of Chiu's Score ${ }^{6}$ of intestinal mucosa (HE, A x100, B x400) 


\section{Discussion}

It has been ten years since the study of Murry et al. ${ }^{2}$ so that the effects of IPr were assessed in the intestine. In 1996, Hotter et al. ${ }^{7}$ published a study in which the IPr was used efficiently to prevent the injuries caused by intestinal ischemia and reperfusion in rats. The authors compared a group in which only intestinal ischemia and reperfusion were performed with another where the IPr was performed and showed lesser injuries in the second group.

Also Sola et al. ${ }^{8}$ proved the benefits of using the IPr in mesenteric ischemia and reperfusion, in a study in which they observed that in the group of rats which underwent ischemia and reperfusion exclusively, the mean value of the intestinal injury level according to Chiu et al. ${ }^{6}$ was 5, and in the group where the IPr was performed the level was 3. The differences between the ischemia/ reperfusion group and the IPr group were statistically significant both in this study and in the study of Sola and col. ${ }^{8}$, although the numbers are quite different. The reason for this difference may be related to the time of ischemia and reperfusion and the IPr. In Sola et al.'s study ${ }^{8}$ the animals underwent a 90-minute ischemia and a 30-minute reperfusion, in contrast with this study, in which a 30-minute ischemia and a 60-minute-reperfusion were performed respectively. Also the IPr was performed differently. Sola et al. ${ }^{8}$ performed the IPr with an only cycle of ischemia and reperfusion lasting ten minutes each, whereas in this study three cycles of ischemia/reperfusion were performed lasting two minutes each.

Moore-Olufemi et al. ${ }^{9}$ also used Chiu et al. ${ }^{6}$ s classification in their study, and had mean values of 3 and 1.2 in the ischemia/reperfusion and IPr groups, respectively. Despite the results being very similar to the ones of this study, the method used was different. They performed ischemia and reperfusion for 30 minutes and six hours, respectively. The IPr was performed with three cycles of ischemia and reperfusion lasting four and ten minutes each, respectively.

Other studies have also shown the capacity of IPr in reducing the intestinal injuries is animals undergoing mesenteric ischemia and reperfusion ${ }^{10,11}$, making it evident that the IPr is able to minimize the damaging effects of the mesenteric ischemia/reperfusion procedure.

The IPo has also presented similar results to the ones of the IPr in preventing the injuries resulting from the ischemia/reperfusion procedure. However, at the moment there is only one study ${ }^{5}$ that shows that this method is probably similar to the IPr as to its effect in the process of the mesenteric blood flow.

Zhao et al. ${ }^{3}$ were the first to report a similarity in results of the IPr and the IPo in preventing the injuries caused by the ischemia/reperfusion procedure. The study was made in dogs, occluding the left lower anterior artery for 60 minutes and performing reperfusion for three hours. The IPr was performed through a cycle of ischemia lasting five minutes and reperfusion for ten minutes. The IPo was performed in three cycles of reperfusion and ischemia lasting 30 seconds each. The infarction area was similar both in the
IPr and in the IPo groups and significantly smaller than in the control group.

During the past 20 years, many treatments for ischemia and reperfusion have been tested without great success ${ }^{12,13}$. The IPr has become a great improvement in the treatment of the Ischemia/Reperfusion Syndrome, however, specifically concerning the mesenteric ischemia and reperfusion, its use is limited, as in most cases ischemia is already present at the moment of the diagnosis ${ }^{14}$. This is the main reason why the IPo is worth being used, because confirming its efficiency in the mesenteric ischemia and reperfusion as well, its clinical use may be of great importance. Despite that, there are no studies assessing its effect on mesenteric ischemia and reperfusion.

In the present study we observed mean values of tissue injuries of 1.2 and 1 in the groups IPr and IPo, respectively, according to the classification of Chiu et al. ${ }^{6}$, in clear contrast with the control group, in which the result was 3.5. It shows that in this study the IPr and the IPo were similar in preventing ischemic and reperfusion injuries in the intestines of rats.

Most of the studies that analyzed the effects of IPo were performed in myocardial ischemia and reperfusion. Donato et al. ${ }^{15}$ compared the IPr and the IPo in rabbits' isolated hearts, performing ischemia and reperfusion for 30 minutes. The IPr was performed in an ischemia/reperfusion cycle of five minutes each, and the IPo in two ischemia/ reperfusion cycles of 30 seconds each. They concluded that the IPo reduces the infarct size as much as the IPr does, without changing the post-ischemic ventricular dysfunction.

These results were also achieved by Darling et al. ${ }^{16}$ in an experimental study assessing the infarct in rabbits' hearts. The IPo was able to minimize the infarct area compared to the control group, performing 4 reperfusion/ ischemia cycles lasting 30 seconds before beginning each reperfusion cycle.

It is believed that the IPo may have a protective effect through the activation of the adenosine receptors, based on studies that showed that by giving antagonists for these receptors during reperfusion, the infarct decreased significantly ${ }^{16}$.

Besides the assessment of IPo in animals' hearts in ischemia and reperfusion, there is also a report of its use in the spinal cord. Huang et al. ${ }^{17}$ showed that the IPo was as efficient as the IPr in preventing the tissue injuries in the spinal cord of rabbits that underwent ischemia and reperfusion. There is also a reports of its use in the renal ${ }^{18}$ and cerebral ${ }^{19}$ tissues with similar results.

The IPo was also analyzed in human beings. Loukogeorgakis et al. ${ }^{29}$ made an experimental study in human beings causing a momentary ischemia in the upper member followed by reperfusion, observing the protective effect of the IPo.

The IPo protective mechanism in the mesenteric ischemia/reperfusion procedure is still not completely clear, yet there are evidences that the IPo may be related to a significant decrease in the levels of malonaldehyde and products related to the lipid peroxidation. These observations suggest a reduction in the production of 
reactive oxygen species (ROS) and less injury mediated by the oxidants with the $\mathrm{IPo}^{3}$.

An abundant production of ROS during the initial phase of reperfusion has been pointed out as the leading reason for the pathogenesis of the tissue injury. The peak in the production of ROS happens between the first and the seventh minute after the beginning of reperfusion, although such substances are detectable in further moments ${ }^{16}$. The IPo acts in this phase in a way that has not been completely explained, probably attenuating the production of ROS through the gradual release of oxygen for the tissues ${ }^{20}$. For this reason, in the present study we performed the IPo right after the ischemia, performing short ischemia/reperfusion cycles, once there is still no definition of which the best length of time is to be used in these cycles, nor is there a number of cycles that would lead to the best results.

Therefore, we believe that the results found in this study showed that, similarly to what is presented in the literature concerning the capacity of the IPr and the IPo to minimize the injuries caused by ischemia and reperfusion in hearts, kidneys, brains, and in the spinal cord, the IPo also minimizes such injuries as much as the IPr in the intestines of rats.

\section{Conclusion}

Preconditioning and postconditioning were equally able to minimize the tissue injury in the intestines of rats that underwent the procedure of mesenteric ischemia and reperfusion.

\section{References}

1. Parks DA, Granger DN. Contributions of ischemia and reperfusion to mucosal lesion formation. Am J Physiol. 1986;250:749-53.

2. Murry CE, Jennings RB, Reimer KA. Preconditioning with ischemia: a delay of lethal cell injury in ischemic myocardium. Circulation. 1986;74:1124-36.

3. Zhao ZQ, Corvera JS, Halkos ME, Kerendi F, Wang NP, Guyton RA, Vinten-Johansen J. Inhibition of myocardial injury by ischemic postconditioning during reperfusion: comparison with ischemic preconditioning. Am J Physiol Heart Circ Physiol. 2003;285:579-88.

4. Schipke JD, Halkos ME, Kerendi F, Gams E, VintenJohansen J. Postconditioning: a brief review. Arch Med Sci. 2006;2:137-45.

5. Santos CHM, Gomes OM, Pontes JCDV, Miiji LNO, Bispo MAF. Post-conditioning: Preliminary results of this new option in the treatment of mesenteric ischemia and reperfusion. Cardiovasc Sci Forum. 2007;2(2):1324.

6. Chiu CJ, McArdle AH, Brown R, Scott HJ, Gurd FN. Intestinal mucosal lesion in low-flow states. Arch Surg. 1970;101:478-83.
7. Hotter G, Closa D, Prados M, Fernandez-Cruz L, Prats N, Gelpi E, Roselló-Catafau J. Intestinal preconditioning is mediated by a transient increase in nitric oxide. Biochem Biophys Res Commun. 1996;222(1):27-32.

8. Sola A, Hotter G, Prats N, Xaus C, Gelpi E, RosellóCatafau J. Modification of oxidative stress in response to intestinal preconditioning. Transplantation. 2000;69:767-72.

9. Moore-Olufemi SD, Kozar RA, Moore FA, Sato N, Hassoun HT, Cox Jr CS, Kone BC. Ischemic preconditioning protects against gut dysfunction and mucosal injury after ischemia/reperfusion injury. Shock. 2005;23(3):258-63.

10. Mallick IH, Yang W, Winslet MC, Seifalian AM. Ischaemic preconditioning improves microvascular perfusion and oxygenation following reperfusion injury of the intestine. Br J Surg. 2005;92:1169-76.

11. Sola A, Alfaro V, Hotter G. Intestinal ischemic preconditioning: Less xanthine accumulation relates with less apoptosis. Apoptosis. 2004;9:353-61.

12. Santos CHM, Gomes OM, Pontes JCDV, Miiji LNO, Higa EI. Uso do propofol (2,6 diisopropilfenol) como inibidor da lesão tecidual na isquemia e reperfusão mesentérica: estudo experimental em ratos. Acta Cir Bras. 2003;18(4):347-54.

13. Santos CHM, Gomes OM, Pontes JCDV. Terapêutica medicamentosa na isquemia e reperfusão mesentérica: revisão da literatura. Rev Bras Coloproctol. 2006;26(1):28-33.

14. Santos CHM. Evolution and challenges in the phisiopatology of the ischemia and reperfusion. Cardiovasc Sci Forum. 2006;1(3):6-8.

15. Donato M, D’Annunzio V, Sabán M, Flor L, Gelpi RJ. Poscondicionamiento: un nuevo mecanismo protector. Su comparación con el precondicionamiento en el infarto experimental. Rev Arg Cardiol. 2004;72(4):25862.

16. Darling CE, Jiang R, Maynard M, Whittaker P, VintenJohansen J, Przyklenk K. "Postconditioning" via stuttering reperfusion limits myocardial infarct size in rabbit hearts: role of ERK 1/2. Am J Physiol Heart Circ Physiol. 2005;289:618-26.

17. Huang H, Zhang L, Wang Y, Yao J, Weng H, Wu H, Chen Z, Liu J. Effect of ischemic post-conditioning on spinal cord ischemic-reperfusion injury in rabbits. Can J Anaesth. 2007;54:42-8.

18. Liu X, Chen H, Zhan B, Xing B, Zhou J, Zhu H, Chen Z. Attenuation of reperfusion injury by renal ischemic postconditioning: the role of NO. Biochem Biophys Res Commun. 2007;359:628-34.

19. Rehni AK e Singh N. Role of phosphoinositide 3-kinase in ischemic postconditioning-induced attenuation of cerebral ischemia-evoked behavioral deficits in mice. Pharmacol Rep. 2007;59:192-8. 
20. Loukogeorgakis SP, Panagiotidou AT, Yellon DM, Deanfiel JE, McAllister RJ. Postconditioning protects against endothelial ischemia-reperfusion injury in the human forearm. Circulation. 2006;113:1015-9.

\section{Correspondence:}

Conflict of interest: none

Carlos Henrique Marques dos Santos

Rua Aluisio de Azevedo, 606

79004050 Campo Grande-MS Brasil

Financial source: none

chmarques@terra.com.br

Received: August 15, 2007

Review: October 10, 2007

Accepted: November 12, 2007

\section{How to cite this article}

Santos CHM, Gomes OM, Pontes JCDV, Miiji LNO, Bispo MAF. The ischemic preconditioning and postconditioning effect on the intestinal mucosa of rats undergoing mesenteric ischemia/reperfusion procedure. Acta Cir Bras. [serial on the Internet] 2008 Jan-Feb;23(1). Available from URL: http://www.scielo.br/acb

\section{*Color figures available from www.scielo.br/acb}

